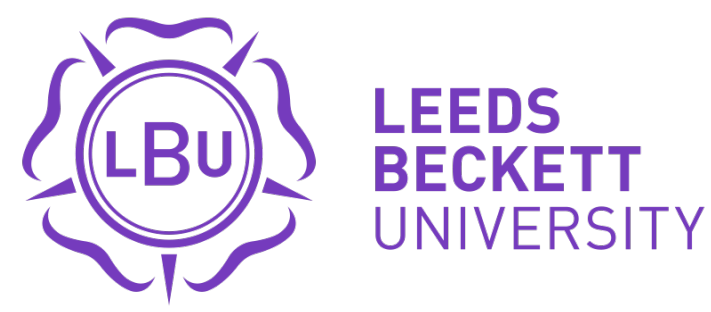

Citation:

Hills, JW and Cahill, J and Lees, J and Freshwater, D (2018) Indices of Change: Analysing the Indexical Properties of Data from Psychotherapy Case Work to Discern Patterns of Therapeutic Change Over Time. In: Computer Supported Qualitative Research: Second International Symposium on Qualitative Research (ISQR 2017). Advances in Intelligent Systems and Computing, 621 . Springer Verlag, pp. 418-424. ISBN 9783319611204 DOI: https://doi.org/10.1007/978-3-319-61121-1_36

Link to Leeds Beckett Repository record:

https://eprints.leedsbeckett.ac.uk/id/eprint/6101/

Document Version:

Book Section (Accepted Version)

ISSN: 2194-5357 This is a post-peer-review, pre-copyedit version of an article published in Advances in Intelligent Systems and Computing. The final authenticated version is available online at: http://dx.doi.org/10.1007/978-3-319-61121-1_36

The aim of the Leeds Beckett Repository is to provide open access to our research, as required by funder policies and permitted by publishers and copyright law.

The Leeds Beckett repository holds a wide range of publications, each of which has been checked for copyright and the relevant embargo period has been applied by the Research Services team.

We operate on a standard take-down policy. If you are the author or publisher of an output and you would like it removed from the repository, please contact us and we will investigate on a case-by-case basis.

Each thesis in the repository has been cleared where necessary by the author for third party copyright. If you would like a thesis to be removed from the repository or believe there is an issue with copyright, please contact us on openaccess@leedsbeckett.ac.uk and we will investigate on a case-by-case basis. 


\title{
Indices of change: analysing the indexical properties of data from psychotherapy case work to discern patterns of therapeutic change over time
}

\author{
John Hills, Dr Jane Cahill, and Dr John Lees of the University of Leeds \\ Prof. Dawn Freshwater of the University of Western Australia \\ Correspondence: John Hills, School of Healthcare, Baines Wing, \\ University of Leeds, LS2 9TJ.hc11j3wh@leeds.ac.uk
}

\begin{abstract}
With reference to semiotic theory, a form of data analysis is proposed that explicitly unpacks the indexical properties of data from psychotherapy case studies. The approach is observed to happen within the therapeutic hour as a co-production between the client and their therapist. Thus analysing the data in this way seeks to address two common charges against traditional research into psychotherapy processes: that it fails to capture the true value of the therapy and lacks the sensitivity to measure outcomes. Two case vignettes will demonstrate the utility of this approach in lived context, with meaning emerging as therapy continues.
\end{abstract}

Keywords: Psychotherapy, case study research, practitioner research, change process research, semiotics

\section{Introduction}

In recent decades, research into the processes and outcomes of psychotherapy have come under increasing criticism for not capturing the value of therapy as understood by practitioners [1], nor generating appropriately sensitive means of measuring outcomes for therapy clients [2]. Research methodologies that studied psychotherapies on the basis that a process, e.g. a psychotherapeutic method, could be tested against an outcome, e.g. whether a client scored better on measures of wellbeing, were not able to capture the complexity of the therapeutic exchange [3]. The now established field of change process research (CPR) considers not just the existence of causal relationships between process and outcome, but also the nature of those relationships; including the sequential nature of change during and across therapy sessions [4]. The analysis of case studies presents particularly rich opportunities to reveal those processes [5]: in addition to capturing the longitudinal nature of the psychotherapy process, case studies offer a form of 'narrative knowing' that it deeply contextualised [6].

Whilst we do not provide a comprehensive review of existing theory in CPR, in this paper we will make reference to several exemplary theoretical approaches. However our purpose is to propose a novel approach to the analysis of case data that we consider to prove complementary to these existing strands. We seek to draw 
attention to a naturalistic form of data analysis that can be observed to take place within the ordinary therapeutic hour. Emergent ideas may be treated by both the client and their therapist to reveal meanings through association and hidden underlying patterns. Such data include the emergence of symptoms, whether psychological or psychosomatic; trigger events associated with those symptoms; happenings within the therapeutic relationship and extra-therapeutic events that apparently heralded change; and the appearance of signs, both material and experiential, associated with change.

\subsection{Indicators of change - existing concepts in change process research}

Skjerve et al's topic change approach takes the transcript data from therapy sessions and ascribes individual utterances e.g. words, phrases etc. according to their topic the focus of conversation [7]. These topics are constituted out of a sequence of utterances that is only broken by a shift to another topic. Once a sequence of utterances is identified to form a topic, this can then be analysed for the perspective taken on the topic e.g. whether the topic is regarded positively or negatively, the emotional content corresponding to it, the client's own appraisal of cause and effect etc. Skjerve et al's method identifies longitudinal recurrences of a topic and seeks to discern shifts in perspective over time.

Significant events studies discern important moments in therapy by reference to multiple sources including client feedback forms on what they considered helpful about therapy and video-recorded interviews [8]. These significant events are considered sequentially as representing the unfolding process between therapist and client through time. These studies typically seek to tie indicators of change within therapy to indicators of good outcome post session and post therapy. It is the concreteness and explicit nature of the significant events that mean this approach is attractive to practitioner researchers in developing 'micro theories' [9].

Gonçalves et al devised a systematic approach to the coding of case data designed to identify what were discerned to be innovative moments in therapy [10]. The concept of an innovative moment emerged from narrative therapy and is defined as the expression of an idea or an action by the client that would not be predicted by the dominant story they tell about themselves. The emergence of an alternative selfnarrative is considered by narrative therapists as a crucial opportunity to facilitate psychotherapeutic change [11].

Whether we seek in individual data an indicator of shift in perspective, a significant event or an innovative moment, a high degree of context sensitivity is necessary on the part of the researcher. Data considered prima facie, without a rich appreciation of the client's life history and styles of meaning-meaning are likely to yield generic inferences. Implicit in the idea of making inferences from explicit and concrete data is the capacity to look beyond the data: to treat them as emergent 'signs' in the therapeutic process and consider what they 'signify' and it is this aspect of the analysis that leads us to consider the indexical properties of case data.

\section{Indexicality}


Indexicality is one of three fundamental sign modalities identified in the semiotic theory of Charles Sanders Peirce; the other two being iconicity and symbolism [12]. An index is a sign that 'points to' an object by virtue of having some contiguity with it in its own context. If one were to look out across the horizon and observe a pillar of smoke it could be reasonably deduced that there was fire below. In this example the visible pillar of smoke serves as an index for the presently invisible fire. Indexicality has utility in disciplines such as medicine - a blood test that revealed abnormal levels of glucose may serve as an index for diabetes; and ecology - the presence of species such as the stonefly or of blood worms in a river serve as indexical of the levels of pollution in the river [13].

\subsection{The utility of indexicality in psychotherapy research and practice}

Psychotherapists similarly observe indices in the stories their clients present to them. When a client reports struggling to get out of bed in the morning, if their attendance at work becomes erratic or they neglect to attend to personal hygiene, these may well be indexical of a state of depression and the therapist will want to explore the greater context in which these signs apparently sit. Likewise if the client reports a new confidence in social situations, that others have noticed them smiling or brighter than before, or that they find they have a 'spring in their step'; these may be considered to be indices of a recovery from depression, that may have been facilitated by shifting patterns of thought, beliefs, relation to others etc. Certain indices may also represent ideas that the client is presently unconscious of or is too ashamed to discuss directly. For example, a client reacts very negatively to a passing comment the therapist made about their relationship with a family member - the intensity of the reaction betrays some presently hidden significance that is not being made explicit in the consulting room.

\subsection{Coding and the emergence of a change orientation}

In coding case data, and particularly in the induction of analytic themes, individual items are implicitly treated as signposts; pointing beyond themselves to greater phenomena. In the therapeutic situation, individual indices will be landed upon because they are perceived to have an implicit semiotic potential e.g. they appear to signify a departure from the client's dominant narrative. This is usually 'felt' between therapist and client before its meanings are explored together. Alves et al described the coding of client utterances as innovative moments where they appeared as 'exceptions to the rule, as they introduce novelty into a client's life' [14]. These indices can be observed to cluster around what Alves et al identify as 'protonarratives' that in successful therapy will evolve into a 'new self-narrative' [15]. These stages may be considered as analogous to tiers of analytic induction. The therapist may explicitly ask the client to consider the bigger picture - "what do you think this tells us about what change looks like for you"? Gonçalves et al describe the client as 'decentering' in this exploratory stage, which is being able to stand back and consider the merits of alternative self-narratives - this allows the client to project themselves into the future and sustain the change [16]. Individual indices may be 
considered as markers representing phases of change e.g. that the client realizes they are going through at the moment; these discernible stages of change have been observed in Styles' assimilation model [17]. In the medium to longer term these phases might be considered to constitute sequential steps in a consistent pattern of change e.g. the establishment of a new self-narrative, such that the client can look back and realise that they are "in a different place" now.

We will now demonstrate the utility of this approach using two case vignettes. The vignettes are the amalgamations of many actual therapeutic cases, with particular details altered as necessary to protect anonymity.

\section{Case vignettes}

\subsection{Maryam}

Maryam was just in her fifties when her husband was diagnosed with a lung cancer within two months he was dead. She came for therapy one year after her husband's death - she'd returned to work relatively soon after his death and recognized she hadn't properly grieved. Now she was beginning to have strange depersonalisation attacks, that felt like 'out of body experiences'. After several sessions' the therapist mentioned, almost in passing that "it sounds really lonely". Although she didn't say anything at the time the therapist's comment had stuck with her - "yes, it really is lonely". When she returned she talked about this with her therapist and they explored further her feelings of alienation. She realized in that session that her strange 'out of body experience' would not be surprising given how disconnected she felt from everybody since her husband's death. Her daughter lived far away, and when friends and colleagues ever asked her how she was she just replied that she was fine - it had become automatic. Maryam understood that she needed to feel reconnected with the world around her and so resolved that if she was asked how she was she wouldn't just automatically reply that she was fine but would be honest.

Maryam came to a session and talked about a dream that she'd had: She was on the way to the train station, using several different modes of transport, as she was to meet her husband who had been away for a long time. After a long and arduous journey she arrived at the station and as she stepped onto the train platform she saw that the train was already disappearing off into the horizon. The meaning for Maryam was clear - in therapy she said that she knew as though for the first time that she would never see her husband again. This helped her to realise that the house she was living in had become a kind of museum to the life that she had shared with her husband, and that she had remained in it in a state of 'suspended animation'. She made the decision to move closer to her daughter, who was herself about to become a mother. One session towards the end of her therapy upon arrival she noticed that she felt genuinely pleased to see the therapist; feeling the warmth of his greeting in return. This felt important to her and upon exploration she realized that it had made her feel that she was no longer phantom-like, but that she had a future. Previous to this she had felt no desire or inclination to have a social life and to return to activities she had 
enjoyed before her husband's death, now she felt in a place to reconnect with old friends and took up lessons in flower arrangement and needlework.

\subsection{Andrew}

Andrew came for therapy after several angry outbursts directed towards family members and colleagues at work about which he felt ashamed and afraid. With the therapist's encouragement Andrew began to tell his life story. Andrew's own father had died when he was just a baby and his mother remarried, going on to have more children. Andrew grew up feeling that he was different, and even that the family would be happier without him in it. The therapist suggested to Andrew that he carried a great deal of anger with him from his childhood that could not be directed legitimately - it wouldn't seem 'fair' to direct his anger towards his stepfather, his mother, or even his deceased father, but as a consequence it spilled out over relatively trivial frustrations. Andrew had noticed that his angry outbursts only occurred when he felt under pressure at work; that his results would be scrutinized as being poor quality in comparison with that of colleagues. When asked to consider when else he might have felt this way he was able, for the first time, to associate this with his childhood experience in the family home. As a consequence he was able to stop seeing his outbursts as frightening and random - he began to understand that they followed a pattern.

The following session Andrew reported an experience when he'd been driving and another driver had selfishly pulled out in front of him on a busy road at rush hour. Andrew had flown into a rage disproportionate to the event. However in a moment of clarity had caught himself - why am I getting so angry? - and recalled the discussion of the previous session. After the event Andrew noticed a profound feeling of calm. He coined a phrase that became a guiding rule for him: "I'm in control, not my anger". As he put this rule into practice, other people began to notice that he seemed brighter and more at ease. Andrew confirmed that he felt different: not having to be perfect all the time; he realized that he was well liked, and that his work was of a good quality, saying for the first time, he really felt like "Andrew".

The included figure overleaf illustrates how from the narrative data of the vignettes, individual elements can be selected for their indexical properties. Each of the indicated phases of change is 'discovered' by Maryam and Andrew and their therapist through curiosity about the indices as they emerge in therapy.

\section{Conclusion}

As is typical in case study research, originating within unique local contexts, questions of generalization need to considered carefully. Stake proposed a form of 'naturalistic generalisability' [18] contingent on the practitioner observing points of contact between a study and their own experience e.g. 'that reminds me of my work with $\mathrm{X}$ and that insight might be useful'. Elliot advocated a research approach similar to the precedents established by a body of case law to discern patterns of 


\title{
Indices of Change
}

\author{
Maryam's story \\ "Yes it really is lonely" \\ "And when she asked \\ me how I was I was just \\ honest with her" \\ Reality sinking in: "I'Il \\ never see him again" \\ "I have to turn the page; \\ I have to write a new \\ chapter" \\ Feeling the warmth of \\ therapist greeting: "it \\ really felt as though \\ you cared"
}

$\frac{-1}{3}$

\section{Client names change orientation}

Client's sense of
self has shifted
Analogous phases of change

Therapist comment appears to spark a new realisation

Moment of lucidity

"Why am I getting so angry?"

Noticing a shift in internal experience

"I felt like this weight had been lifted from my shoulders"

\section{Andrew's story}

"I suppose I always felt like that at home"

"I'm in control, not my anger"

"For the first time I really feel like Andrew, you know?"

psychotherapeutic change and the conditions that facilitate change between cases [19]. In the language of the present study: a unique case study may be considered as indexical of more generalized therapeutic phenomena. Thus, we will now apply this novel analytic approach within a case series of psychotherapeutic work undertaken by the first author. In addition to identifying patterns of change within cases, attention will also be drawn to analogous patterns of change between cases: to what extent are these patterns congruous; to what extent do they diverge?

In this paper we have demonstrated how a naturally-occurring exploration of the indexical properties of case data takes place between the client and their therapist in the ordinary therapeutic hour. Furthermore we have proposed that this same indexical analysis may be utilised in complementary fashion with existing approaches to data analysis within the Change Process Research tradition. The deliberate and purposeful exploration of the indexical properties of case data may also provide a useful tool for counsellors and psychotherapists in their training, for example in increasing their sensitivity to the signs (indices) that emerge within the therapeutic conversation and may point the way to significant therapeutic change. 


\section{References}

1. A.C. Bohart, K.L. Tallman, G. Byock, \& T. Mackrill. The "Research Jury" Method: The Application of the Jury Trial Model to Evaluating the Validity of Descriptive and Causal Statements about Psychotherapy Process and Outcome. Pragmatic Case Studies in Psychotherapy, Volume 7, Module 1, Article 8, pp. 101-144 (2011)

2. Green, D. Making the case for using personalised outcome measures to track progress in psychotherapy, European Journal of Psychotherapy \& Counselling, 39-57 (2016)

3. Elliott, R. Psychotherapy change process research: Realizing the promise, Psychotherapy Research, 20:2, 123-135 (2010)

4. Ibid

5. Skjerve, J., Reichelt, S. \& McLeod, J. Topic change processes in psychotherapy: a case study approach, Qualitative Research in Psychology, 13:4, 271-288 (2016)

6. McLeod, J. Case Study Research. Sage Publications : London (2010)

7. Skjerve, J., Reichelt, S. \& McLeod, J. Topic change processes in psychotherapy: a case study approach, Qualitative Research in Psychology, 13:4, 271-288 (2016)

8. Elliott, R. Psychotherapy change process research: Realizing the promise, Psychotherapy Research, 20:2, 123-135 (2010)

9. Ibid

10. Gonçalves, M.M., Ribeiro, A.P, Mendes, I. Matos, M. \& Santos, A. Tracking novelties in psychotherapy process research: The innovative moments coding system, Psychotherapy Research, 21:5, 497-509 (2011)

11. Ribeiro A.P. \& Gonçalves M.M., Commentary Innovation and Stability within the Dialogical Self: The Centrality of Ambivalence. Culture and Psychology (2010)

12. Peirce, C.S.: A Syllabus of Certain Topics of Logic. Alfred Mudge \& Son, Boston (1903)

13. Nuffield Foundation, http://www.nuffieldfoundation.org/practicalbiology/monitoring-water-pollution-invertebrate-indicator-species

14. Alves, D., Fernández-Navarro, P., Ribeiro, A.P., Ribeiro, E. \& Gonçalves, M.M. Ambivalence and Innovative Moments in Grief Psychotherapy. Psychotherapy 2014, vol.51, number 2, pp308-321 (2014)

15. Ibid

16. Gonçalves, M.M., Ribeiro, A.P, Mendes, I. Matos, M. \& Santos, A. Tracking novelties in psychotherapy process research: The innovative moments coding system, Psychotherapy Research, 21:5, 497-509 (2011)

17. Styles, W.B. Assimilation and the process of outcome: Introduction to a special section. Psychotherapy Research, August 2006; 16(4): 389 _392 (2006)

18. Stake, R.E. The Case Study Method in Social Inquiry in Gomm, R., Hammersley, M. \& Foster, P.. Case Study Method: Key Issues, Key Texts. Sage Publications, London (2000)

19. Elliott, R. Hermeneutic Single-Case Efficacy Design, Psychotherapy Research, 12:1, $1-21(2002)$ 